\title{
¿Es útil el rastreo de escoliosis en los adolescentes?
}

A Population-Based Study of School Scoliosis Rastreo.
Yawn B, Yawn R, Hodge D, Kurland M, Shaughnessy W, Ilstrup D, Jacobsen S. JAMA 1999:282;1427-32

\section{Objetivo}

Determinar la efectividad de un programa de rastreo de escoliosis en la comunidad escolar.

\section{Diseño}

Estudio de cohorte retrospectivo.*

\section{Lugar}

Escuelas públicas y privadas en Rochester, Minnesota, EE.UU.

\section{Participantes}

Ingresaron 2934 niños que estaban en jardín de infantes o primer grado entre 1979 - 1981. Los niños fueron seguidos hasta los 19 años o hasta que dejaron el distrito escolar.

\section{Descripción del test en estudio y test de referencia}

El rastreo de escoliosis fue realizado por enfermeras capacitadas para tal fin, supervisadas por un médico traumatólogo. El examen se realizó mediante la inspección de asimetrías, y desde 1986 mediante el uso del escoliómetro que cuantificaba la prominencia costal. Aquellos alumnos con una desviación obvia o un resultado mayor a seis unidades en la lectura del escoliómetro eran reexaminados en dos a cuatro semanas. Si en esta nueva revisación persistía la desviación o la lectura mayor a seis unidades, eran referidos por medio de cartas a sus padres a una consulta profesional. Cuando el examen no era normal pero no se cumplían los criterios de derivación se envió un segundo tipo de carta donde se notificaba a los padres que sus hijos serían reexaminados en 6 meses en vez de la práctica habitual anual, recordando a aquellos padres con niños en el $9^{\circ}$ grado que no se haría otro rastreo escolar. Este segundo tipo de carta no recomendaba específicamente una evaluación profesional. Para evaluar la efectividad del pro- grama de rastreo, se utilizaron datos de las consultas médicas y tratamiento de la escoliosis de la comunidad.

\section{Medición de resultados principales}

Número de niños diagnosticados o tratados por escoliosis, basados en los resultados del rastreo anual entre el $5^{\circ}$ y $9^{\circ}$ grado, relacionándolos con los registros médicos de la comunidad. Características operativas del programa de rastreo.

\section{Resultados}

De los 2242 niños rastreados, $92(4,1 \%)$ fueron referidos para otra evaluación. De estos, 68 (74\%) tienen documentado una evaluación médica o quiropráctica para escoliosis. El rastreo escolar identificó a 5 de los 9 niños tratados por escoliosis, pero fueron derivados otros 87 que no recibieron tratamiento alguno. La incidencia acumulativa* de diagnóstico de escoliosis en esta población fue de 1,8\% (IC 95\% 1,2$2,3 \%$ ) para curvas de más de $10^{\circ} ; 1.0 \%$ (IC $95 \% 0.6-1.5 \%$ ) para curvas de hasta $20^{\circ}$ y $0.4 \%$ (IC $95 \% 0.1-0.6 \%$ ) para curvas mayores a $40^{\circ}$. Los niños que fueron tratados para la escoliosis constituyeron un $0.4 \%$. El valor predictivo positivo del programa de rastreo escolar para identificar los casos de escoliosis tratado fue de $0.05 \%$ (IC 95\% 0.048-0.052), con la necesidad de rastrear 448 niños para identificar un niño que recibirá tratamiento (número necesario a rastrear). El porcentaje de concordancia del rastreo a través de los años varió entre un 7 y un $30 \%$.

\section{Conclusiones}

En la población estudiada el rastreo escolar de escoliosis identificó niños que luego recibieron tratamiento, aunque derivó muchos que no recibieron tratamiento posterior. Estos resultados deben ser considerados para tomar la decisión de realizar el rastreo escolar de escoliosis.

Fuente de financiamiento: US Public Healtr Service, National Institutes of Health, Bethseda, Olmsted MCH Care Foundation, y Mayo Foundation, Rochester, Minn.

\section{COMENTARIO}

Este estudio fue realizado como un intento de evaluar la evidencia acerca de la efectividad del rastreo de escoliosis en niños y adolescentes. Debido a la falta de ensayos aleatorizados y estudios observacionales acerca de los resultados de los programas de rastreo, la fuerza de tareas preventiva de EE.UU no llegó a conclusión alguna acerca de su indicación. ${ }^{1}$ La baja incidencia poblacional de escoliosis tratada (simiLar a la incidencia reportada en este estudio), llevó a varios países europeos a abandonar los programas de rastreo de esta patología El presente estudio fue realizado en la ciudad de Rochester, Minnesota, en escuelas públicas y privadas. Su comunidad es predominantemente blanca. De los 2934 niños que ingresaron a la escuela, 2242 cumplieron los requisitos para ser incorporados dentro del programa. De los 692 no ingresados, 689 no lo hicieron por dejar el distrito escolar antes de entrar al $7^{\circ}$ grado o por no permanecer en él por lo menos dos años (los 3 restantes ya tenían diagnóstico de escoliosis previo al inicio del programa).

Esto limita la validez interna* del mismo, pero a su vez refleja la realidad y la alta tasa de migración interna existente en los EE.UU. De todos modos no invalida los resultados ya que no parece haber razones por las cuales los chicos que desarrollarían escoliosis tendrían más o menos riesgo de mudarse que el resto de la población.

De los 2242 niños rastreados, sólo 139 fueron sometidos a la consulta para evaluación de escoliosis. Los 139 niños corresponden a 68 niños derivados por el programa, 62 niños que habían recibido la "carta de aviso" y 9 donde consta una consulta sin haber sido notificado ni derivados por el programa.

Como resultado final a los 19 años, se realizó diagnóstico de la patología en 41 casos. De todos estos, tres presentaban diagnóstico previo a la puesta en marcha del programa y seis fueron identificado fuera del programa de rastreo. Entre los 32 niños diagnosticados dentro del programa, cinco recibieron tratamiento; mientras que entre los nueve diagnosticados fuera del mismo cuatro fueron tratados.

Como conclusión, se puede decir que un programa de rastreo de escoliosis identifica a algunos chicos que recibirán tratamiento pero deriva a muchos más que no lo harán. Plantear un ensayo aleatorizado es muy ambicioso e improbable de llevarse a cabo. Por lo tanto, cada comunidad individual deberá decidir que es lo apropiado y posible de hacer en base en los mejores datos disponibles. A pesar de este estudio, el rastreo de escoliosis permanece como otra de las tantas area grises de la medicina.

*Ver glosario

Dra. Irene Gopen Servicio de Medicina Familiar. Hospital Francés, Buenos Aires. 